\title{
Angiopoietin-like protein 2 expression is suppressed by angiotensin II via the angiotensin II type 1 receptor in rat cardiomyocytes
}

\author{
SHUYA WANG ${ }^{1,2}$, YING LI $^{1}$, WEI MIAO ${ }^{1}$, HONG ZHAO ${ }^{1}$, FENG ZHANG ${ }^{1}$, \\ NAN LIU ${ }^{1,2}$, GUOHAI SU ${ }^{1}$ and XIAOJUN CAI ${ }^{1,2}$ \\ ${ }^{1}$ Department of Cardiovascular Medicine, Jinan Central Hospital Affiliated to Shandong University; \\ ${ }^{2}$ Shandong University School of Medicine, Jinan, Shandong 250013, P.R. China \\ Received February 17, 2016; Accepted July 11, 2016
}

DOI: $10.3892 / \mathrm{mmr} .2016 .5544$

\begin{abstract}
The present study aimed to determine the inhibitory effects of angiotensin II (AngII) on angiopoietin-like protein 2 (Angpt12) in rat primary cardiomyocytes, and to investigate the potential association between angiotensin II type 1 receptor (AT1R) and these effects. Cardiomyocytes were isolated from 3-day-old Wistar rats, and were cultured and identified. Subsequently, the expression levels of Angptl2 were detected following incubation with various concentrations of AngII for various durations using western blotting, reverse transcription-quantitative polymerase chain reaction, enzyme-linked immunosorbent assay and immunofluorescence. Finally, under the most appropriate conditions (100 nmol/1 AngII, $24 \mathrm{~h}$ ), the cardiomyocytes were divided into six groups: Normal, AngII, AngII + losartan, normal + losartan, AngII + PD123319 and normal + PD123319 groups, in order to investigate the possible function of AT1R in Angptl2 suppression. Losartan and PD123319 are antagonists of AT1R and angiotensin II type 2 receptor, respectively. The statistical significance of the results was analyzed using Student's t-test or one-way analysis of variance. The results demonstrated that Angptl2 expression was evidently suppressed $(\mathrm{P}<0.05)$ following incubation with $100 \mathrm{nmol} / \mathrm{l}$ AngII for $24 \mathrm{~h}$. Conversely, the expression levels of Angptl2 were significantly increased in the AngII + losartan group compared with the AngII group $(\mathrm{P}<0.01)$. However, no significant difference was detected between the AngII + PD123319, normal + losartan or normal + PD123319 groups and the normal group. The present in vitro study indicated that AngII was able to suppress Angpt12 expression,
\end{abstract}

Correspondence to: Dr Xiaojun Cai, Department of Cardiovascular Medicine, Jinan Central Hospital Affiliated to Shandong University, 105 Jiefang Road, Jinan, Shandong 250013, P.R. China

E-mail: tianchr@126.com

Key words: angiopoietin-like protein 2, angiotensin II, angiotensin II type 1 receptor, cardiomyocytes, cardiac hypertrophy whereas losartan was able to significantly reverse this decrease by inhibiting AT1R.

\section{Introduction}

The renin-angiotensin-aldosterone system (RAAS) has an important role in homeostasis of the cardiovascular system (1). Angiotensin II (AngII) has an indispensable role in the RAAS, and is well recognized for its key function in cardiovascular and renal physiology (2). AngII not only mediates immediate physiological effects, including vasoconstriction and blood pressure regulation, but is also involved in inflammation, atherosclerosis, endothelial injury and heart failure (3). Heart failure is a complex clinical syndrome that lowers quality of life. It can be caused by hypertension, myocardial disease, coronary artery disease, or numerous other related heart disorders. RAAS inhibitors are widely used in the clinical therapy of heart failure. However, the exact mechanism underlying their effects remains to be fully elucidated. As a part of the RAAS, the effects of AngII are mediated by its interaction with angiotensin II type 1 receptor (AT1R) and angiotensin II type 2 receptor (AT2R) (4,5). The majority of the effects of AngII are mediated by AT1R, including extracellular matrix formation, increased vasopressin secretion, vasoconstriction, cardiac hypertrophy and cardiac contractility (6). AT1R is widespread in various organs and tissues, such as the liver, adrenal cortex and some areas of the brain. Vascular and myocardial tissues express more AngII compared with other tissues $(7,8)$. Notably, a previous study revealed that angiotensin AT1 receptor-associated protein (ARAP1), which is also referred to as angiopoietin-like protein 2 (Angptl2), was suppressed in the kidney vasculature by AngII, which was mediated by AT1R (9). In this previous study, localization of Angpt 2 was detected in the kidney of mice and humans, in order to confirm that Angptl2 expression can be regulated by AngII.

Angptl2 was initially cloned, expressed and characterized in 1999 (10). It is a member of the angiopoietin-like family, which contains eight members of glycoproteins. It is a secreted circulating protein with a molecular weight of $57 \mathrm{kDa}$, which consists of 493 amino acids (10-12). Members 
of the angiopoietin-like family possess a structure containing a typical $\mathrm{N}$-terminal helical coiled-coil domain, a short linker peptide and a $\mathrm{C}$-terminal globular fibrinogen-like domain, which is analogous to angiopoietins (10). Angptl2 has been detected in numerous mouse organs, with the highest expression levels found in the heart, aorta, kidney and adrenal gland (9). In addition, it has been reported that the distribution of Angptl2 is consistent with AT1R. The Angptl2 protein interacts with AT1R, and promotes AT1R translocation to the plasma membrane, facilitating increased AT1R surface expression in vitro (13). However, the expression levels of Angptl2 have not been detected in vitro following stimulation with AngII.

In the present study, a $48 \mathrm{~h}$ stimulation with $100 \mathrm{nmol} / \mathrm{l}$ AngII was initially conducted to observe alterations in Angpt12 expression; these conditions are considered the most appropriate for use in the kidney in vitro (9). The present study hypothesized that Angptl2 expression would be suppressed in rat cardiomyocytes following AngII treatment via AT1R. The most appropriate conditions (100 nmol/1 AngII, $24 \mathrm{~h}$ ) were identified in the present study, which were shown to significantly suppress Angpt12 expression. Several experiments were subsequently conducted to explore the role of AT1R in this process. Finally, a conclusion was drawn that the expression of Angpt12 may be suppressed by AngII via AT1R in rat cardiomyocytes.

\section{Materials and methods}

Isolation and culture of cardiomyocytes. Male, 3-day-old Wistar rats used in the present study were provided by the Animal Center of Shandong University (Jinan, China). All animal experiments were performed in accordance with the National Institutes of Health Guide for the Care and Use of Laboratory Animals, and were approved by the ethics committee of Shandong University. Primary neonatal rat cardiomyocyte cultures were prepared as described in a previous study (14). Briefly, cardiomyocytes from Wistar rats were cultured in Dulbecco's modified Eagle's medium (Gibco; Thermo Fisher Scientific, Inc., Shanghai, China) supplemented with $10 \%$ fetal bovine serum (Gibco; Thermo Fisher Scientific, Inc., Brisbane, Australia), $100 \mathrm{U} / \mathrm{ml}$ penicillin-streptomycin (Beijing Solarbio Science \& Technology Co., Ltd., Beijing, China) at $37^{\circ} \mathrm{C}$ in an atmosphere containing $5 \% \mathrm{CO}_{2}$. The cardiomyocytes were incubated at a density of $5 \times 10^{5}$ cells $/ \mathrm{ml}$. Subsequent experiments were conducted on first generation primary cardiomyocytes.

Preparation of cultured cells. To illustrate the effects of AngII on Angpt12 expression, AngII (Sigma-Aldrich Chemie GmbH, Hamburg, Germany) was added to the culture medium in six-well plates containing cardiomyocytes $\left(5 \times 10^{5}\right.$ cells $\left./ \mathrm{ml}\right)$ at the following final concentrations: 0, 50, 100 and $200 \mathrm{nmol} / \mathrm{l}$ for $24 \mathrm{~h}$. In addition, cells were incubated with $100 \mathrm{nmol} / \mathrm{l}$ AngII for 0, 6, 24 or $48 \mathrm{~h}$. The culture medium from each condition was collected. Total protein was extracted from the rat cardiomyocytes using radioimmunoprecipitation assay buffer (Beyotime Institute of Biotechnology, Beijing, China), which contained 0.1 M phenylmethylsulfonyl fluoride. After washing with phosphate-buffered saline (PBS), grinding, lysis and centrifugation (at $4^{\circ} \mathrm{C}, 13,000 \mathrm{x}$ g, $15 \mathrm{~min}$ ), the supernatant was collected. Protein concentrations were measured using the bicinchoninic acid assay (Protein Assay kit; Beyotime Institute of Biotechnology), in which bovine serum albumin was used as a standard. After adding $5 \mathrm{X}$ loading buffer [sodium dodecyl sulfate polyacrylamide gel electrophoresis (SDS-PAGE) Loading Buffer/Lane Markers; Beyotime Institute of Biotechnology], the mixture was boiled in water at $100^{\circ} \mathrm{C}$ for $8 \mathrm{~min}$, and was stored at $-80^{\circ} \mathrm{C}$.

Immunofluorescence. $\alpha$-Smooth muscle actin ( $\alpha$-SMA) was used as a marker to identify cardiomyocytes. The extracted cells were identified as cardiomyocytes by observing cellular morphology using immunofluorescent staining (14-16). Briefly, the cells were rinsed with PBS and were fixed with 4\% paraformaldehyde for $15 \mathrm{~min}$. Subsequently, they were permeabilized with $0.3 \%$ Triton X-100 for $20 \mathrm{~min}$. Nonspecific antibody binding sites were blocked by incubating the cells in normal goat serum (Beijing Zhongshan Jinqiao Biotechnology Co., Ltd., Beijing, China) for $30 \mathrm{~min}$. The cells were then incubated with $\alpha$-SMA (1:200; cat. no. 6487; Cell Signaling Technology, Inc., Danvers, MA, USA) and Angptl2 antibodies (1:400; cat. no. sc-292811; Santa Cruz Biotechnology, Inc.) overnight in a humidified incubator at $4^{\circ} \mathrm{C}$. The following day cells were incubated with Alexa Fluor 488 goat anti-rabbit immunoglobulin G secondary antibody (cat. no. A-11034; Thermo Fisher Scientific, Inc., Waltham, MA, USA) for $35 \mathrm{~min}$ at $37^{\circ} \mathrm{C}$ and were washed three times with PBS. After the final wash, nuclei were stained with 4',6-diamidino-2-phenylindole (DAPI; Invitrogen; Thermo Fisher Scientific, Inc., Waltham, MA, USA) for $5 \mathrm{~min}$. Images were acquired under an inverted fluorescence microscope (Olympus Corporation, Tokyo, Japan).

Reverse transcription-quantitative polymerase chain reaction $(R T-q P C R)$. Total RNA was extracted from the rat cardiomyocytes following various treatment conditions using TRIzol reagent (Invitrogen; Thermo Fisher Scientific, Inc.). RNA concentration was determined using the Thermo Scientific Nano Drop 2000/2000c Spectrometer (Thermo Fisher Scientific, Inc., Wilmington, DE, USA). cDNA was obtained by RT using Takara PrimeScript RT Reagent kit with gDNA Eraser (Takara Biotechnology Co., Ltd., Dalian, China) according the manufacturer's specifications. qPCR was then performed to detect Angptl2 and glyceraldehyde-3-phosphate dehydrogenase (GAPDH) expression using the Applied Biosystems 7300 fast real-time PCR system (Applied Biosystems; Thermo Fisher Scientific, Inc., Waltham, MA, USA). The mRNA expression levels of Angptl2 were normalized to GAPDH mRNA expression levels. qPCR amplification was carried out in a total volume of $20 \mu \mathrm{l}$, containing $10 \mathrm{ml}$ SYBR Premix Ex Taq (Takara Biotechnology Co., Ltd.), $0.4 \mathrm{ml}$ each of forward and reverse primers, $6.8 \mathrm{ml}$ PCR-grade sterile water and $2 \mathrm{ml}$ DNA templates.

The oligonucleotide primers used were as follows: Rat Angpt12, forward 5'-gaagcatgaagcctgctc-3', reverse, 5'-cagcag tccaagccaccagta-3'; and rat GAPDH, forward 5'-gcaagagagagg ccctcag-3', and reverse 5'-tgtgagggagatgctcagtg-3'. The cycling conditions were as follows: Initial denaturation at $95^{\circ} \mathrm{C}$ for $30 \mathrm{sec}, 40$ cycles at $95^{\circ} \mathrm{C}$ for $5 \mathrm{sec}, 60^{\circ} \mathrm{C}$ for $34 \mathrm{sec}$ and $95^{\circ} \mathrm{C}$ for $15 \mathrm{sec}$, followed by $60^{\circ} \mathrm{C}$ for $1 \mathrm{~min}$ and $95^{\circ} \mathrm{C}$ for $15 \mathrm{sec}$. The $\Delta \mathrm{Cq}$ 
values were obtained by subtracting the quantification cycle (Cq) value of GAPDH from the $\mathrm{Cq}$ value of Angptl2. The $\Delta \mathrm{Cq}$ values of each treatment group were further compared with those of the controls $(\Delta \Delta \mathrm{Cq})$ to obtain relative quantification of the target gene expression (17).

SDS-PAGE and western blotting. Protein samples $(100 \mu \mathrm{g})$ extracted from rat cardiomyocytes were separated by $10 \%$ SDS-PAGE and were transferred onto polyvinylidene fluoride membranes (EMD Millipore, Billerica, MA, USA). The membranes were blocked in 5\% non-fat milk at room temperature for $1 \mathrm{~h}$. The membranes were then immunoblotted with Angptl2 (1:400; cat. no. sc-292811; Santa Cruz Biotechnology, Inc., Dallas, TX, USA) and GAPDH antibodies (1:10,000; cat. no. 60004-1-Ig; Wuhan Sanying Biotechnology, Wuhan, China) at $4^{\circ} \mathrm{C}$ overnight, followed by goat anti-rabbit (1:3,000; cat. no. LK2001; Sanjian, Tianjin, China) and rabbit anti-mouse (1:5,000; cat. no. GTX29170; GeneTex, Inc., Irvine, CA, USA) secondary antibodies for $1 \mathrm{~h}$. Subsequently, the images were detected using Luminol Reagent (EMD Millipore) and FluorChem E (ProteinSimple, San Jose, CA USA). Analysis of western blotting was conducted using ImageJ software (version 2.1.4.7; National Institutes of Health, Bethesda, MD, USA).

Regulation of Angptl2 expression using AT1R and AT2R antagonists. To further explore the role of AT1R in Angpt12 expression regulation, additional experiments were conducted. AT1R antagonist (losartan; 10 $0^{-4} \mathrm{~mol} / \mathrm{l}$; Sigma-Aldrich, St. Louis, MO, USA) and AT2R antagonist (PD123319; $10^{-4} \mathrm{~mol} / \mathrm{l}$; Abcam, Cambridge, UK) were added to the cells $45 \mathrm{~min}$ prior to treatment with AngII (100 nmol/l). After $24 \mathrm{~h}$, protein, RNA and culture media were extracted. The normal + losartan/PD123319 groups were used as negative controls.

Enzyme-linked immunosorbent assay (ELISA). The culture medium was harvested from the culture plates of various treatment groups. Angptl2 expression was measured using an Angpt12 detection kit (Human ANGPTL2 ELISA kit; R\&D Systems, Inc., Minneapolis, MN, USA), according to the manufacturer's protocol. Angptl2 levels were calculated according to a standard curve and were corrected using an blank well.

Statistical analysis. Student's t test was used to analyze differences between two groups. One-way analysis of variance with Bonferroni's tests was used to analyze more than two groups. All analyses were performed using GraphPad Prism v 5.01 software (GraphPad Software, Inc., La Jolla, CA, USA). All the experimental data are presented as the mean \pm standard deviation and the mean values were calculated according to at least three independent experiments. $\mathrm{P}<0.05$ was considered to indicate a statistically significant difference.

\section{Results}

Identification of cardiomyocytes. Primary cardiomyocytes were isolated from 3-day-old rats. The cellular morphology was observed under a microscope. Cardiomyocytes were shown to grow in a group, which adhered to the bottom of the dish (black arrow, Fig. 1A). In addition, the cardiomyocytes were detected to produce a certain beating rhythm under the microscope. The identification of cardiomyocytes was also verified by detecting $\alpha$-SMA expression, which was chosen as a label of cardiomyocytes. Following incubation with $\alpha$-SMA antibodies, the cells were stained with a secondary antibody, which was equipped with fluorescence (green), and DNA was stained with DAPI (blue). Fibroblasts cultured with cardiomyocytes exhibited negative staining for $\alpha$-SMA. Images were captured at a magnification of x200 (Fig. 1B). Stained cells were counted under a microscope in four fields. The purity of cardiomyocytes in the isolated primary cells was $\sim 94 \%$.

Effects of various AngII concentrations on cardiomyocytes. To explore the effects of AngII on cardiomyocytes, the cells were incubated with various concentrations of AngII $(0,50$, 100 or $200 \mathrm{nmol} / \mathrm{l}$ ) for $24 \mathrm{~h}$, or were incubated with $100 \mathrm{nmol} / \mathrm{l}$ AngII for various durations $(0,6,24$ or $48 \mathrm{~h})$. As shown in Fig. 2A, the mRNA expression levels of Angptl2 were initially quantified in the cardiomyocyte samples, which were divided into two groups: The normal group and the cardiomyocyte group, which was stimulated with $100 \mathrm{nmol} / \mathrm{l} \mathrm{AngII} \mathrm{for} 48 \mathrm{~h}$. The expression levels of Angpt12 were measured by RT-qPCR and were normalized to GAPDH. Treatment with $100 \mathrm{nmol} / \mathrm{l}$ AngII resulted in a decrease in Angptl 2 mRNA expression $(0.604 \pm 0.061)$ in rat cardiomyocytes compared with in the normal group $(1.069 \pm 0.047 ; \mathrm{P}<0.05$; Fig. 2A). As shown in Fig. 2B and C, the protein expression levels of Angptl2 were measured following incubation for various durations with various AngII concentrations, respectively. The results demonstrated that following incubation with $100 \mathrm{nmol} / \mathrm{l} \mathrm{AngII}$ for $24 \mathrm{~h}$, the protein expression levels of Angptl2 (0.59 \pm 0.044$)$ were more obviously decreased than under any of the other conditions, as compared with the normal group $(1.78 \pm 0,029$; $\mathrm{P}<0.05$; Fig. $2 \mathrm{~B}$ and $\mathrm{C}$ ). An ELISA was also conducted to detect Angptl2 expression, in order to verify this trend. Culture media samples were used, which were collected from cells treated under the same conditions as for western blotting (Fig. 2D and E). The results of the ELISA were consistent with those of western blotting. Immunofluorescence was used to further verify the trend; DNA was stained with DAPI (blue) and Angptl2 was stained with green fluorescence (Fig. 2F). Blue and green fluorescence were assessed simultaneously under a magnification of x400. Representative images were captured under identical exposure parameters. ImageJ software was used to analyze the fluorescence (Fig. 2G). The expression levels of Angtpl2 were markedly decreased following treatment with $100 \mathrm{nmol} / \mathrm{l}$ AngII for $24 \mathrm{~h}$.

Role of AT1R and AT2R antagonists. Additional experiments were conducted to determine the possible role AT1R had with regards to this phenomenon. Following treatment with losartan $\left(10^{-4} \mathrm{~mol} / \mathrm{l}\right)$ and PD123319 $\left(10^{-4} \mathrm{~mol} / \mathrm{l}\right)$, the alterations in Angpt12 expression were detected in cardiomyocytes using western blotting, ELISA, RT-qPCR and immunofluorescence. Analysis of western blotting revealed that the protein expression levels of Angtpl2 were significantly decreased in the AngII group $(0.17 \pm 0.012)$ compared with in the normal group $(0.52 \pm 0.018 ; \mathrm{P}<0.05$; 
A

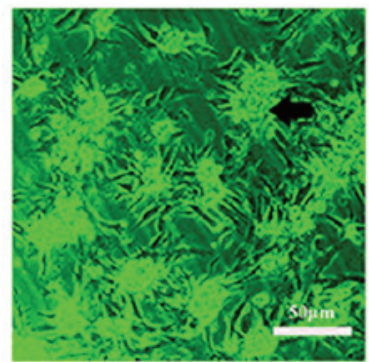

B

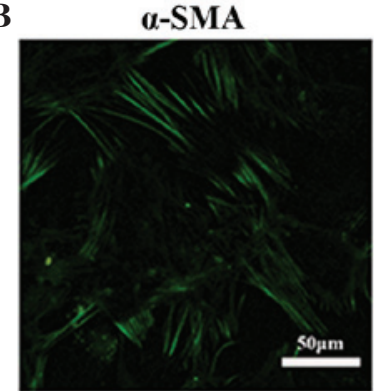

DAPI

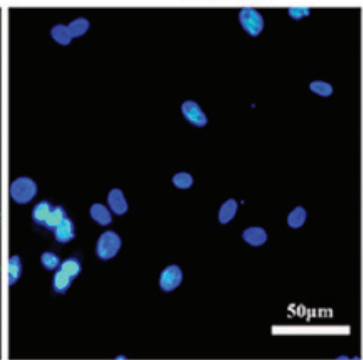

Merge

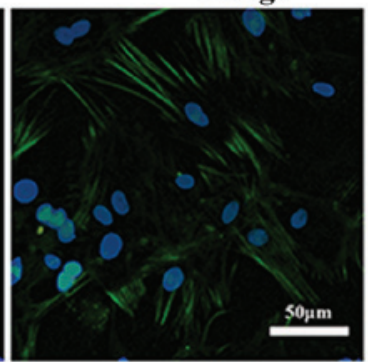

Figure 1. Identification of cardiomyocytes. (A) Cardiomyocytes were observed growing in a group and were revealed to beat in a certain rhythm under a microscope (black arrow). (B) $\alpha$-Smooth muscle actin ( $\alpha$-SMA) was used to label cardiomyocytes and was detected by immunofluorescence. Magnification, $\mathrm{x} 200$. The purity of isolated primary cardiomyocytes was $29 \%$. DAPI, 4',6-diamidino-2-phenylindole.

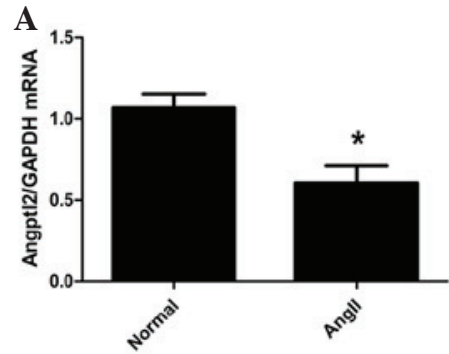

D

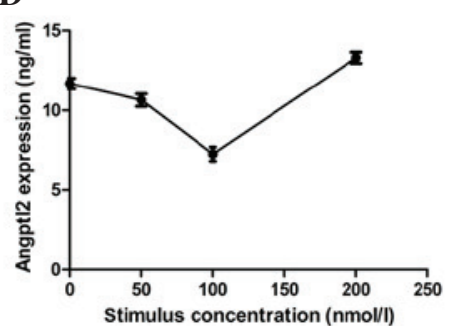

$\mathbf{E}$

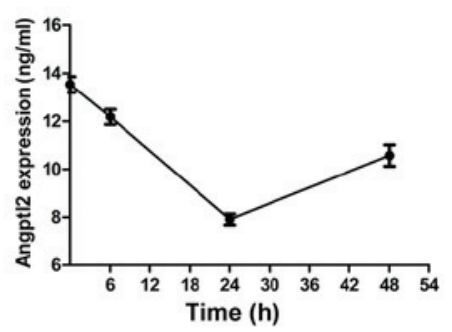

B

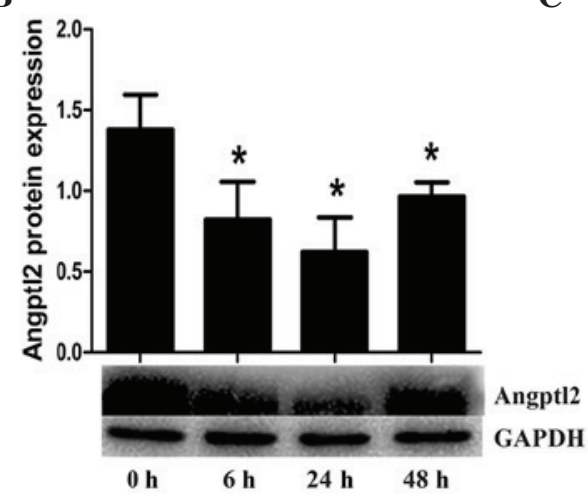

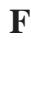
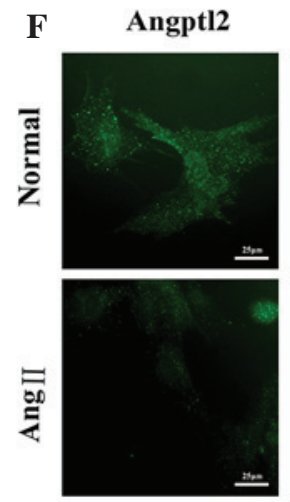

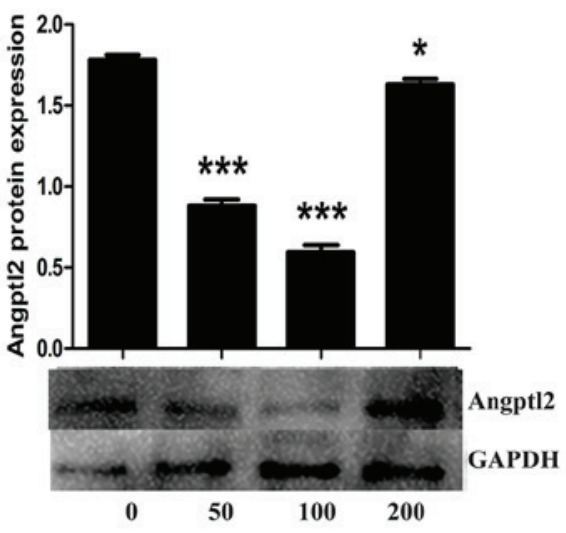

Figure 2. Effects of various angiotensin II (AngII) concentrations on cardiomyocytes. (A) mRNA expression levels of angiopoietin-like protein 2 (Angptl2) were measured by reverse transcription-quantitative polymerase chain reaction (RT-qPCR) and were normalized to glyceraldehyde 3-phosphate dehydrogenase (GAPDH) following treatment with $100 \mathrm{nmol} / 1$ AngII for $48 \mathrm{~h}$. cDNA sample size was $100 \mathrm{ng}$. Protein expression levels of Angptl2 were detected by western blotting (B) following treatment with $100 \mathrm{nmol} / 1 \mathrm{AngII}$ for various durations $(0,6,24$ and $48 \mathrm{~h}$; protein sample size, $100 \mu \mathrm{g})$, (C) or with various concentrations of AngII (0, 50, 100 or $200 \mathrm{nmol} / \mathrm{l})$ for $24 \mathrm{~h}$ (protein sample size, $40 \mu \mathrm{g}$ ). Enzyme-linked immunosorbent assay for Angptl2 was used to verify the trend detected by RT-qPCR and western blotting following treatment of cells with (D) various concentrations of AngII (E) for various durations (sample size of each group, $10 \mu \mathrm{l}$ ). (F) Immunofluorescence was used to confirm the conclusions of these experiments. Green staining, Angptl2; blue staining, 4',6-diamidino-2-phenylindole (DAPI); magnification, $\mathrm{x} 400$. (G) Fluorescence intensity was analyzed using ImageJ software. ${ }^{*} \mathrm{P}<0.05,{ }^{* *} \mathrm{P}<0.01$ and ${ }^{* * *} \mathrm{P}<0.001$, vs. the corresponding control group ( $0 \mathrm{~h}$ or $0 \mathrm{nmol} / \mathrm{l})$.

Fig. 3A). Conversely, the AngII + losartan group exhibited increased Angptl2 expression (0.55 \pm 0.016$)$ compared with the AngII group ( $\mathrm{P}<0.05$; Fig. 3A). Angpt12 expression in the normal + losartan group $(0.61 \pm 0.0091)$ was similar to that in the normal group ( $\mathrm{P}>0.05$; Fig. 3A). The Angpt12 expression level in each group is shown in Fig. 3B. The expression level of Angpt12 in the AngII group was decreased significantly compared with the normal group $(\mathrm{P}<0.05)$, whereas the AngII + PD123319 group exhibited no difference compared with the AngII group. Additionally, the normal + PD123319 exhibited no significant difference compared with the normal group. RT-qPCR was also 
A

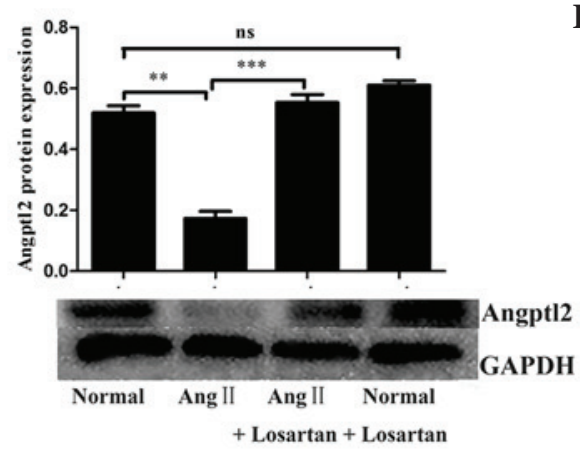

C

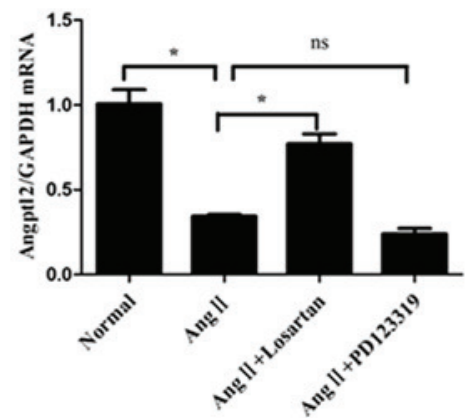

B

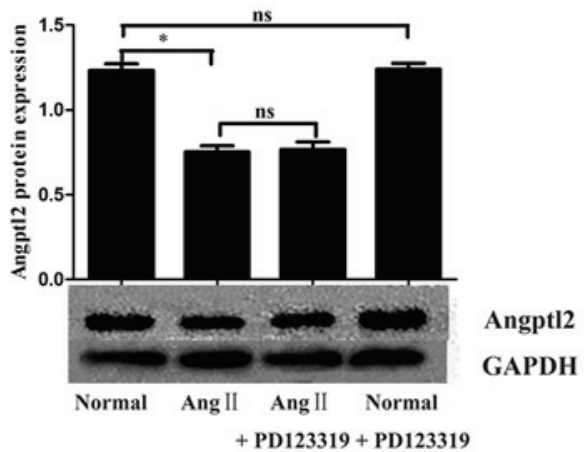

D

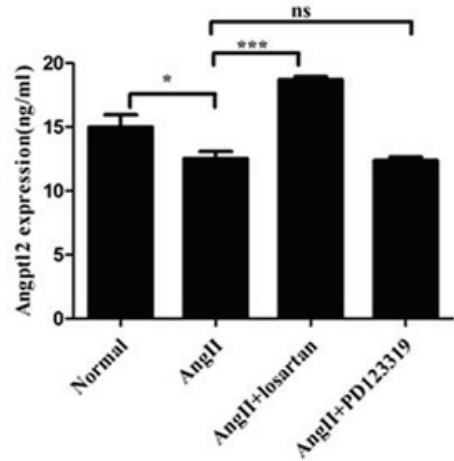

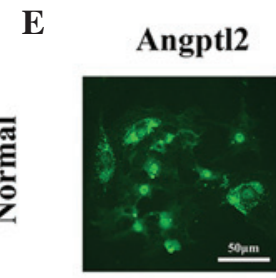
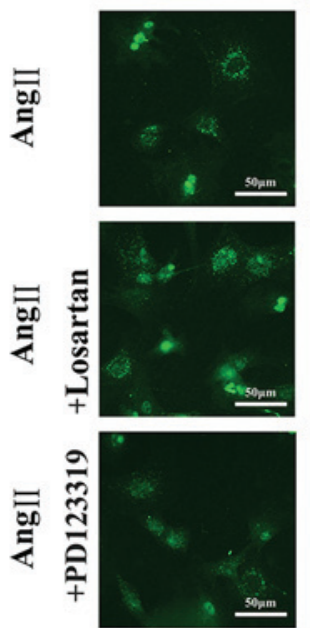

DAPI
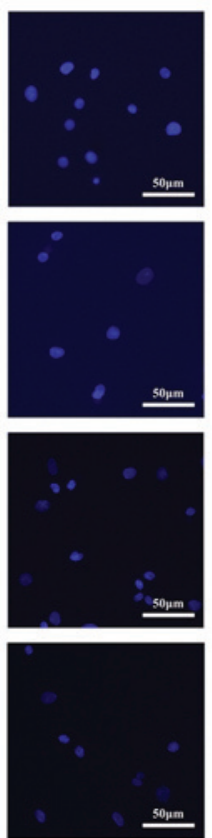

Merge
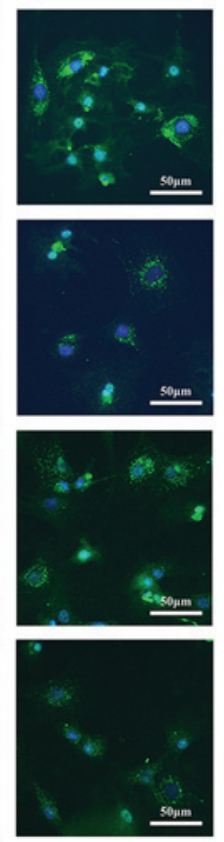

F

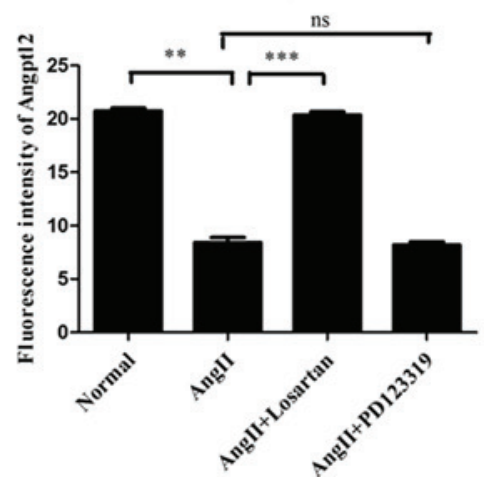

Figure 3. Role of angiotensin II type 1 receptor (AT1R) and angiotensin II type 2 receptor (AT2R) antagonists. To determine the possible underlying mechanisms associated with the effects of angiotensin II (AngII) on angiopoietin-like protein 2 (Angptl2), the cells were divided into six groups: Normal, AngII $(100 \mathrm{nmol} / \mathrm{l})$, AngII $(100 \mathrm{nmol} / \mathrm{l})+$ losartan $\left(10^{-4} \mathrm{~mol} / \mathrm{l}\right)$, AngII $(100 \mathrm{nmol} / \mathrm{l})+$ PD123319 $\left(10^{-4} \mathrm{~mol} / \mathrm{l}\right)$, normal + losartan $\left(10^{-4} \mathrm{~mol} / \mathrm{l}\right)$ and normal + PD123319 $\left(10^{-4} \mathrm{~mol} / \mathrm{l}\right)$. (A and B) Angpt12 protein expression was detected in each group by western blotting (protein sample size, $\left.40 \mu \mathrm{g}\right)$. (C) Angptl2 mRNA expression was detected in each group by reverse transcription-quantitative polymerase chain reaction (cDNA sample size, $100 \mathrm{ng}$ ), (D) enzyme-linked immunosorbent assay (culture media volume, $10 \mu \mathrm{l}$ ) and (E) immunofluorescence. (F) ImageJ software was used to analyze fluorescence intensity; blue and green fluorescence were assessed simultaneously (magnification, $\mathrm{x} 200$ ). Data are presented as the mean \pm standard deviation. ${ }^{*} \mathrm{P}<0.05,{ }^{* *} \mathrm{P}<0.01$ and ${ }^{* * *} \mathrm{P}<0.001$, comparison indicated by brackets. ns, not significant. GAPDH, glyceraldehyde 3-phosphate dehydrogenase.

performed to detect Angpt12 expression, and the results are displayed in Fig. 3C. Furthermore, the secretion of Angptl2 was detected using an ELISA. The ELISA results were consistent with those of western blotting (Fig. 3D). Immunofluorescence was performed concurrently and the results are presented in Fig. 3E. DNA was stained with DAPI (blue), and Angpt12 was stained using an antibody equipped with fluorescence (green). Representative images were captured under identical exposure parameters, and ImageJ was used to analyze fluorescence intensity (Fig. 3F). The RT-PCR 
and immunofluorescence results were in accoradance with the western blot analysis. These data suggest that Angptl2 is suppressed by AngII (100 nmol/1, $24 \mathrm{~h})$, and this effect may be reversed by losartan (AT1R antagonist) but not by PD123319 (AT2R antagonist).

\section{Discussion}

Cardiac hypertrophy is an adaptive response that occurs in physical and pathological conditions, which ultimately results in heart failure. Pathological cardiac hypertrophy, which is caused by hypertension, myocardial infarction, cardiomyopathy or structural heart diseases, is associated with cardiac structural remodeling (18). Higher plasma levels of AngII have been detected in the heart of patients with cardiac hypertrophy and heart failure (19). AngII is involved in the RAAS and has vital roles in several diseases; the majority of effects of AngII are mediated by AT1R. Angpt12 is a member of the Angptl family, which has a vital role in AT1R recycling (20). Furthermore, Huang et al (21) revealed that Angpt12 serum levels in patients with heart failure are independently associated with heart failure. Therefore, Angpt12 may be related to cardiac hypertrophy; however, there is currently no evidence to verify its relationship with heart failure.

The results of the present study suggested that Angpt12 is suppressed by AngII in cardiomyocytes in vitro. The study speculated that AT1R may be the key factor mediating the effects of AngII in this process. To test this assumption an antagonist of AT1R was used, and an antagonist of AT2R was used as a negative control. The normal + losartan/PD123319 groups were also the negative control groups to testify the conclusion of this study. Analysis of the experimental data supported the aforementioned hypothesis.

Angpt12 is well recognized in several chronic diseases, including atherosclerosis, diabetes, metabolic disorders and cancer, due to its harmful proinflammatory properties (22). Angptl2 has been reported to act as a key inflammatory factor in activating adhesion molecule expression, thus increasing circulating cholesterol levels and accelerating the development of atherosclerotic plaques in dyslipidemic and pre-atherosclerotic mice (23). Angptl2 expression may increase following stimulation with AngII according to its harmful properties (21). However, the present study demonstrated that AngII had the opposite effect on Angptl2 expression. Furthermore, a previous study reported that Angptl2 expression in the heart and aorta remained unchanged following stimulation with AngII (9). This contradiction is probably due to the use of chronic infusion of AngII in vivo, whereas the present study was conducted in vitro, with cardiomyocytes being treated with $100 \mathrm{nmol} / \mathrm{l}$ AngII for $24 \mathrm{~h}$. Various exposure times and concentrations may also account for this discrepancy. This phenomenon can be explored by further in vivo and in vitro studies.

The expression levels of ARAP1 have been reported to be suppressed by AngII in mice kidney vasculature (9). ARAP1, is an alternative name for Angptl2; this name is typically only used when referring to the interaction with AngII (22). The present study focused on the interaction of Angpt12 with AT1R. Previous studies have proposed the possibility of additional intracellular proteins that may interact with AT1R, and have an imperative role in receptor recycling (24-30). Angptl2 can modulate AT1R expression at the cell surface, enhancing its sensitivity to AngII $(31,32)$. It has also been reported that Angpt12 is downregulated during sepsis, causing decreased renal sensitivity to AngII and eventually contributing to hypotension, demonstrating that Angptl2 takes part in AT1R recycling (33). These results suggested that Angpt12 promotes AT1R recycling to the plasma membrane (34) and enhances sensitivity to AngII in various pathophysiological processes. In the present study, following stimulation with $100 \mathrm{nmol} / \mathrm{l}$ AngII for $24 \mathrm{~h}$, Angpt12 expression levels were decreased; however, Angpt12 expression was increased following treatment with an AT1R antagonist. Therefore, it may be hypothesized that under AngII stimulation, AngII promotes the hypertrophy of cardiomyocytes by interacting with active AT1R, thus cardiomyocytes express less Angpt12 in order to decrease AT1R sensitivity so as to adapt to the excessive amount of active AT1R.

In conclusion, the results of the present in vitro study suggested that Angpt12 expression is suppressed by AngII, which may be mediated by AT1R activation. In normal cardiomyocytes, treatment with AT1R or AT2R antagonist exerted no significant effect on Angpt12 expression. Therefore, Angpt12 may serve as a local modulator of AT1R function and may contribute to cardiomyocyte adaptations in response to increased levels of circulating AngII. In the present study, Angpt12 expression was demonstrated to be more markedly suppressed following treatment with $100 \mathrm{nmol} / \mathrm{l} \mathrm{AngII} \mathrm{for}$ $24 \mathrm{~h}$, as compared with any other conditions. Following stimulation with $200 \mathrm{nmol} / \mathrm{l}$ AngII, Angptl2 expression was increased compared with treatment with $100 \mathrm{nmol} / \mathrm{l}$ AngII for $24 \mathrm{~h}$; therefore, the suppression of Angptl 2 by AngII was shown to be attenuated by time extension. The results of the present study also suggested that Angpt12 expression is suppressed by AngII at lower concentrations, and this effect, which is mediated by AT1R, may have a role at a certain concentration range. Another possibility is that, as time prolongs and concentration increases, AT1R may saturate, and Angpt12 would increase to improve the sensitivity of AT1R to AngII. Further studies may explore the possibility that Angpt12 expression is altered under lower and higher concentrations of AngII in vitro and in vivo, and it is hypothesized that various mechanisms will lead to this effect. Since AT1R, which is an indispensable component of the RAAS, has a central role in several pathophysiological processes, Angpt12 may be involved in the process of cardiovascular diseases and function. The results of the present study may be used to propose a novel therapeutic method for the treatment of cardiovascular disease by decreasing Angpt12. Undoubtedly, numerous aspects of the present study require verification. The concentration range of AngII that suppressed Angpt12 in cardiomyocytes is not definite, and the explicit mechanism underlying this phenomenon is not certain. AngII is able to suppress Angpt12 in cardiomyocytes, and its effects on cardiomyocytes require further research. In addition, although Angpt12 and ARAP1 are encoded by the same gene, this does not necessarily mean that the matching proteins are entirely identical. More extensive experiments and further clinical proof are required to support this speculation in future studies. 


\section{Acknowledgements}

The authors would like to thank the Department of Cardiology and Central Lab of Jinan Central Hospital for technical assistance. The present study was supported by grants from the Natural Science Foundation of Shandong Province (grant no. ZR2013HM003), the Natural Science Foundation of China (grant no. 81170087), the National Natural Science Funds for Young Scholar (grant no. 81200211) and the National Natural Science Foundation of China Grant (grant no. 81270175$)$.

\section{References}

1. Cai Y, Wang Y, Xu J, Zuo X and Xu Y: Down-regulation of ether-a-go-go-related gene potassium channel protein through sustained stimulation of AT1 receptor by angiotensin II. Biochem Biophys Res Commun 452: 852-857, 2014.

2. Welter H, Huber A, Lauf S, Einwang D, Mayer C, Schwarzer JU, Köhn FM and Mayerhofer A: Angiotensin II regulates testicular peritubular cell function via AT1 receptor: A specific situation in male infertility. Mol Cell Endocrinol 393: 171-178, 2014.

3. Matsoukas MT, Potamitis C, Plotas P, Androutsou ME, Agelis G, Matsoukas $\mathbf{J}$ and Zoumpoulakis P: Insights into AT1 receptor activation through AngII binding studies. J Chem Inf Model 53 2798-2811, 2013.

4. Reid IA: Interactions between ANG II, sympathetic nervous system, and baroreceptor reflexes in regulation of blood pressure. Am J Physiol 262: E763-E778, 1992.

5. Siragy HM: AT(1) and AT(2) receptors in the kidney: Role in disease and treatment. Am J Kidney Dis 36 (3 Suppl 1): S4-S9, 2000.

6. Schmieder RE, Hilgers KF, Schlaich MP and Schmidt BM: Renin-angiotensin system and cardiovascular risk. Lancet 369 1208-1219, 2007.

7. Messerli FH, Weber MA and Brunner HR: Angiotensin II receptor inhibition. A new therapeutic principle. Arch Intern Med 156: 1957-1965, 1996.

8. Goodfriend TL, Elliott ME and Catt KJ: Angiotensin receptors and their antagonists. N Engl J Med 334: 1649-1654, 1996.

9. Doblinger E, Höcherl K, Mederle K, Kattler V, Walter S, Hansen PB, Jensen B and Castrop H: Angiotensin AT1 receptor-associated protein Arapl in the kidney vasculature is suppressed by angiotensin II. Am J Physiol Renal Physiol 302: F1313-F1324, 2012.

10. Kim SS, Choi IG, Kim SH and Yu YG: Molecular cloning, expression, and characterization of a thermostable glutamate racemase from a hyperthermophilic bacterium, Aquifex pyrophilus. Extremophiles 3: 175-183, 1999.

11. Tabata M, Kadomatsu T, Fukuhara S, Miyata K, Ito Y, Endo M, Urano T, Zhu HJ, Tsukano H, Tazume H, et al: Angiopoietin-like protein 2 promotes chronic adipose tissue inflammation and obesity-related systemic insulin resistance. Cell Metab 10 178-188, 2009.

12. Kadomatsu T, Tabata M and Oike Y: Angiopoietin-like proteins: Emerging targets for treatment of obesity and related metabolic diseases. FEBS J 278: 559-564, 2011.

13. Guo DF, Chenier I, Tardif V, Orlov SN and Inagami T: Type 1 angiotensin II receptor-associated protein ARAP1 binds and recycles the receptor to the plasma membrane. Biochem Biophys Res Commun 310: 1254-1265, 2003.

14. Matsui H, Yokoyama T, Tanaka C, Sunaga H, Koitabashi N, Takizawa T, Arai M and Kurabayashi M: Pressure mediated hypertrophy and mechanical stretch up-regulate expression of the long form of leptin receptor (ob-Rb) in rat cardiac myocytes. BMC Cell Biol 13: 37, 2012.

15. Tao T, Wang X, Liu M and Liu X: Myofibrillogenesis regulator-1 attenuates hypoxia/reoxygenation-induced injury by repairing microfilaments in neonatal rat cardiomyocytes. Exp Cell Res 337: 234-242, 2015
16. Cao T, Gao Z, Gu L, Chen M, Yang B, Cao K, Huang H and Li M: AdipoR1/APPL1 potentiates the protective effects of globular adiponectin on angiotensin II-induced cardiac hypertrophy and fibrosis in neonatal rat atrial myocytes and fibroblasts. PLoS One 9: e103793, 2014.

17. Livak KJ and Schmittgen TD: Analysis of relative gene expression data using real-time quantitative PCR and the 2(-Delta Delta C(T)) Method. Methods 25: 402-408, 2001.

18. Oka T, Akazawa H, Naito AT and Komuro I: Angiogenesis and cardiac hypertrophy: Maintenance of cardiac function and causative roles in heart failure. Circ Res 114: 565-571, 2014.

19. Serneri GG, Boddi M, Cecioni I, Vanni S, Coppo M, Papa ML, Bandinelli B, Bertolozzi I, Polidori G, Toscano T, et al: Cardiac angiotensin II formation in the clinical course of heart failure and its relationship with left ventricular function. Circ Res 88: 961-968, 2001.

20. Guo DF, Chenier I, Lavoie JL, Chan JS, Hamet P, Tremblay J, Chen XM, Wang DH and Inagami T: Development of hypertension and kidney hypertrophy in transgenic mice overexpressing ARAP1 gene in the kidney. Hypertension 48: 453-459, 2006.

21. Huang CL, Wu YW, Wu CC, Hwang JJ and Yang WS: Serum Angiopoietin-like protein 2 concentrations are independently associated with heart failure. PLoS One 10: e0138678, 2015.

22. Thorin-Trescases N and Thorin E: Angiopoietin-like-2: A multifaceted protein with physiological and pathophysiological properties. Expert Rev Mol Med 16: e17, 2014.

23. Farhat N, Thorin-Trescases N, Mamarbachi M, Villeneuve L, Yu C, Martel C, Duquette N, Gayda M, Nigam A, Juneau M, et al: Angiopoietin-like 2 promotes atherogenesis in mice. J Am Heart Assoc 2: e000201, 2013.

24. Ali MS, Sayeski PP, Dirksen LB, Hayzer DJ, Marrero MB and Bernstein KE: Dependence on the motif YIPP for the physical association of Jak2 kinase with the intracellular carboxyl tail of the angiotensin II AT1 receptor. J Biol Chem 272: 23382-23388, 1997.

25. Sano T, Ohyama K, Yamano Y, Nakagomi Y, Nakazawa S, Kikyo M, Shirai H, Blank JS, Exton JH and Inagami T: A domain for $\mathrm{G}$ protein coupling in carboxyl-terminal tail of rat angiotensin II receptor type 1A. J Biol Chem 272: 23631-23636, 1997.

26. Venema RC, Ju H, Venema VJ, Schieffer B, Harp JB, Ling BN, Eaton DC and Marrero MB: Angiotensin II-induced association of phospholipase Cgamma1 with the G-protein-coupled AT1 receptor. J Biol Chem 273: 7703-7708, 1998.

27. Smith RD, Hunyady L, Olivares-Reyes JA, Mihalik B, Jayadev S and Catt KJ: Agonist-induced phosphorylation of the angiotensin AT1a receptor is localized to a serine/threonine-rich region of its cytoplasmic tail. Mol Pharmacol 54: 935-941, 1998.

28. Smith RD, Baukal AJ, Zolyomi A, Gaborik Z, Hunyady L, Sun L, Zhang M, Chen HC and Catt KJ: Agonist-induced phosphorylation of the endogenous AT1 angiotensin receptor in bovine adrenal glomerulosa cells. Mol Endocrinol 12: 634-644, 1998.

29. Chaki S, Guo DF, Yamano Y, Ohyama K, Tani M, Mizukoshi M, Shirai $\mathrm{H}$ and Inagami T: Role of carboxyl tail of the rat angiotensin II type $1 \mathrm{~A}$ receptor in agonist-induced internalization of the receptor. Kidney Int 46: 1492-1495, 1994.

30. Hunyady L, Bor M, Balla T and Catt KJ: Identification of a cytoplasmic Ser-Thr-Leu motif that determines agonist-induced internalization of the AT1 angiotensin receptor. J Biol Chem 269: 31378-31382, 1994.

31. Castrop H: Angiotensin receptor-associated proteins: Local modulators of the renin-angiotensin system. Pflugers Arch 465: $111-119,2013$

32. Higuchi S, Ohtsu H, Suzuki H, Shirai H, Frank GD and Eguchi S: Angiotensin II signal transduction through the AT1 receptor: Novel insights into mechanisms and pathophysiology. Clin Sci (Lond) 112: 417-428, 2007.

33. Mederle K, Schweda F, Kattler V, Doblinger E, Miyata K, Höcherl K, Oike Y and Castrop H: The angiotensin II AT1 receptor-associated protein Arap1 is involved in sepsis-induced hypotension. Crit Care 17: R130, 2013.

34. Guo DF, Sun YL, Hamet P and Inagami T: The angiotensin II type 1 receptor and receptor-associated proteins. Cell Res 11: 165-180, 2001. 